\title{
STUDENT UNDERSTANDINGS OF EVIDENCE-BASED MANAGEMENT: WAYS OF DOING AND BEING
}

This paper advances the literature on Evidence Based Management (EBMgt) by exploring how students understand EBMgt. We conduct a qualitative inductive study of undergraduate students who were introduced to EBMgt and applied evidence-based processes as part of an introductory management course. Our findings identify four qualitatively different student understandings of EBMgt: (1) EBMgt as an unrealistic way of doing management; (2) EBMgt as a way of doing management in particular situations; (3) EBMgt as a generally useful way of doing management; and (4) EBMgt as an ideal way of being a manager. We find that variations in student understanding are based upon perceptions of the utility of evidencebased processes, the stance taken towards scientific evidence as a form of knowledge, and the focus of reflection about the practice of EBMgt. By opening up insight into the how undergraduate students understand and make sense of EBMgt as ways of doing and being, we contribute to the theoretical literature on EBMgt and to the practice of EBMgt teaching and learning and offer new paths for future research.

Keywords: Evidence-based management, evidence-based practice, student learning, undergraduate teaching, qualitative research 
Educators and scholars have focused increasing attention on evidence-based management (EBMgt) over the past decade. EBMgt is defined as 'making decisions through the conscientious, explicit, and judicious use of four sources of information: practitioner expertise and judgment, evidence from the local context, a critical evaluation of the best available research evidence, and the perspectives of those people who might be affected by the decision' (Briner, Denyer, \& Rousseau, 2009: 19). The growth and acceptance of EBMgt as an important topic in management education is evident in publications such as AMLE’s recent special issue (Rynes, Rousseau, \& Barends, 2014), the Oxford Handbook of EBMgt (Rousseau, 2012), and specialist textbooks (Latham, 2009; Pearce, 2013), as well as the establishment of an international community of scholars, educators and practitioners interested in evidence-based approaches.

The literature can be divided into two broad streams that reflect the maturing of EBMgt and the need for 'educators who help develop the professional skills on which EBMgt rests' (Rousseau, 2012: xxv). The first stream of literature establishes the conceptual boundaries of EBMgt and engages in scholarly debate and advocacy of why management educators should teach evidenceinformed decision making (Morrell \& Learmonth, 2015; Pfeffer \& Sutton, 2007; Rousseau, 2006; Rousseau \& McCarthy, 2007; Tourish, 2013). While some scholars note that evidence is a contested concept within management and organizational studies (Learmonth, 2006; Morrell, 2008; Reay, Berta, \& Kohn, 2009), this literature stream predominantly argues that teaching students about EBMgt develops them into 'more sophisticated and informed consumer(s) of business ideas' (Pfeffer \& Sutton, 2006: 36) able to critically appraise the legitimacy of information sources (Kepes, Bennett, \& McDaniel, 2014; Kovner, Elton, \& Billings, 2000; Tranfield, Denyer, \& Smart, 2003). Through learning about EBMgt, it is proposed that students gain the skills needed to translate research evidence into local solutions to organizational problems, thereby becoming more effective managers and problem-solvers in the future (Baba \& HakemZadeh, 2012; Barends \& Briner, 2014; Graen, 2009). While this literature stream acknowledges that some management students may resist learning about EBMgt for various reasons (Rousseau \& McCarthy, 2007), scholars' accounts of learning are 
relatively superficial. Insight into how students understand and make sense of course content and materials related to EBMgt is lacking, especially at the undergraduate level where novice business students are introduced to evidence-based practice for the first time.

The second stream of literature moves beyond advocating for the theoretical utility of EBMgt to exploring the adoption and use of EBMgt by management educators. Attention has tended to focus either on examining the uptake of EBMgt in programs and specialist courses (Briner \& Walshe, 2014; Charlier, Brown, \& Rynes, 2011; Dietz et al., 2014) or on specific classroom practices, teaching techniques and assessment strategies through which EBMgt can be taught (Erez \& Grant, 2014; Gamble \& Jelley, 2014; Goodman \& O'Brien, 2012; Wright, Middleton, Greenfield, Williams, \& Brazil, 2016a). A core aim of this literature stream is to advance the translation of the concept of EBMgt into educator practice. Yet, although this literature is underpinned by an assumption that students learn about EBMgt through exposure to the concept by educators, very few empirical studies have collected data from, or about, students (an exception is Wright, Nichols, McKechnie, \& McCarthy, 2013). Thus, little is known about the impact of educators' teaching choices on student understanding of EBMgt.

Together, these two literature streams have advanced the field of management education by enriching debates on the nature, use and value of EBMgt and by building a foundation for its incorporation into management courses, curricula and teaching practices. However, much more work is needed to improve pedagogy with respect to EBMgt. Both literature streams have taken an educator-focused rather than student-focused perspective and offer limited explanation of how students make sense of their course learning experiences with the concept of EBMgt. This gap in the literature is greatest for undergraduate students, which constrains capacity to develop these students, as future managers, into evidence-based practitioners. Further advances in the theory and practice of EBMgt require management educators who are 'striving continually to learn about students' understanding [of EBMgt] and the effects of teaching on it' (Ramsden, 2003: 8). As EBMgt matures, educators must move beyond the current 'first step’ (Erez \& Grant, 2014: 105) of first-person 
accounts of teaching experiences with EBMgt to build empirically-grounded pedagogical insights into how different types of students interpret, comprehend and experience EBMgt. Therefore, we aim to contribute to the literature by addressing the following research question: How do undergraduate students understand EBMgt?

We investigate our research question through a qualitative inductive study of undergraduate students' experience with applying EBMgt and reflecting on its meaning and utility for practice. The context for our study is a large undergraduate introductory management course. In response to our research question, our findings reveal important variations in students' understanding of EBMgt after being introduced to and applying the concept for the first time. The undergraduate students in our study expressed four qualitatively different understandings: (1) EBMgt is an unrealistic way of doing management; (2) EBMgt is a way of doing management in particular situations; (3) EBMgt is a generally useful way of doing management; and (4) EBMgt is an ideal way of being a manager. Our findings show an individual student's understanding is based upon their perception of the utility of evidence-based decision processes, their stance towards scientific evidence as a form of knowledge, and the focus of their reflection about the practice of EBMgt.

Our findings make two contributions to the literature. Our first contribution lies in our shift away from the dominant educator perspective on EBMgt to exploration of the student perspective. Whereas EBMgt scholars in the past have asked, 'how can we teach EBMgt in ways that are enlivening and convincing?’ (Bartenuk, 2014: 102), our study reframes the question away from educators to consider how students understand EBMgt when we teach it. In doing so, we extend the literature by opening up insight into the qualitatively different understandings of EBMgt that students construct, based on their accounts of experience with EBMgt when engaging with a particular management case, in the context of a pull approach to teaching. While prior scholars have speculated about the positive and negative experiences that students have when educators try to teach EBMgt (Erez \& Grant, 2014; Goodman \& O'Brien, 2012; Rousseau \& McCarthy, 2007), our findings advance the literature and generate new pedagogical knowledge by conducting systematic and 
rigorous analysis of students accounts of their own experience with EBMgt. We uncover variations in student's understandings of EBMgt that have important implications for the theory and practice of EBMgt and its teaching by management educators.

Our second contribution arises from our focus on gaining deeper insight into the undergraduate student experience of EBMgt. While the EBMgt literature has tended to emphasise the postgraduate, executive and MBA levels (Charlier et al., 2011; Dietz et al., 2014; Graen, 2009; Klimoski \& Amos, 2012; Rubin \& Dierdorff, 2009) and specialist courses (Briner \& Walshe, 2014; Glaub, Frese, Fischer, \& Hoppe, 2015; Trank, 2014), we broaden the scope of EBMgt teaching and learning to include novice management students in generalist first-year undergraduate courses. Undergraduate students are 'the next generation of future managers' and the uptake of EBMgt in organizations depends, in no small part, on engaging them in evidence-based practice during their studies (Rousseau \& McCarthy, 2007). However, whether it is possible to teach EBMgt meaningfully in undergraduate programs has long been a source of debate.

On the one hand, introductory management and organizational behaviour courses are ‘critical to developing students’ schemas for management’ (Thompson, Purdy, \& Fandt, 1997: 218). Thus, exposing novice students to EBMgt at this early stage of study has potential benefit in seeding evidence-based ways of doing, thinking and behaving as part of their future professional practice (Dall'Alba, 2009). On the other hand, in comparison to students in more advanced undergraduate courses (Kachra \& Schneitz, 2008), students in first-year introductory courses are unfamiliar with the theory and practice of management (Wright \& Gilmore, 2012). They also lack knowledge and personal experience of organizational contexts (Thompson et al., 1997). Our findings contribute to the literature by offering new insight into students’ experiences of EBMgt when it is taught early in undergraduate programs. We show that undergraduate students have the capacity to engage with EBMgt very early in their programs of study through specifically targeted learning and assessment activities in generalist introductory courses. We also bring to the surface the variations in understandings of EBMgt that are likely to arise from this targeted early exposure. 
The remainder of the paper is structured as follows. First, we present a theoretical background to the teaching and learning of EBMgt in management education. Next, we describe and justify our methods for investigating our research question by collecting and analysing qualitative data in a large introductory management course. We then report our findings regarding the four qualitatively different understandings of EBMgt as ways of doing and being. Finally, the paper concludes with a discussion of how our findings offer theoretical contributions to the literature, practical implications for teaching and learning of EBMgt, and new paths for future research.

\section{THEORETICAL BACKGROUND}

EBMgt has become 'influential' in the field of management education even as scholarly conversations have opened up about its assumptions and pedagogical implications (Morrell \& Learmonth, 2015: 526). In this section, we outline the major developments in the literature regarding teaching of EBMgt and we call attention to the need for greater insight into the impact of teaching on student understanding of evidence-based practice.

\section{Teaching EBMgt as Professional Education}

Scholars have looked to the literature on professional education for pedagogical insight to guide teaching of EBMgt. Borrowing from Schulman's (2005) work on signature pedagogies in professions, Trank (2014: 381) has proposed that introducing EBMgt into management education 'in broad strokes ... fits with the ideal that professional schools create a signature pedagogy ... [which] must measure up to the standards not just of the academy, but also of particular professions'. According to Schulman (2005: 52), signature pedagogies are defined as 'the types of teaching that organize the fundamental ways in which future practitioners are educated for their new professions'. Given that signature pedagogies 'implicitly define what counts as knowledge in the field and how things become known’ (Schulman, 2005: 54), proponents argue EBMgt should be approached as a pedagogical means for reclaiming professionalism in business education (Trank \& Rynes, 2003). In doing so, teaching of EBMgt may revive the original founding mission of American business schools of legitimizing management as a profession (Khurana, 2007). 
Conceptualizing EBMgt as fundamental to professional education assumes that management students are 'apprentice professionals' who educators are preparing 'to be active consumers and users of research as professionals’ after they graduate (Trank, 2014: 384). How management graduates ‘earn their pay as professionals’ (Graen, 2009: 255) is justified and legitimated by their ability to apply evidence-based processes to decisions in organizational contexts (Abbott, 1988). Consistent with the literature on professional education and training (Dall'Alba, 2009; Schon, 1983), learning about EBMgt can be staged along a novice to expert pathway (Benner, 1982). Novice management students are introduced to the concept of EBMgt and 'progress toward greater expertise by developing more systematic and valid models of professional practice' through a continuous cycle of knowledge acquisition, practice, and reflection (Rousseau \& McCarthy, 2007: 92). As students move along the novice to expert pathway, they try on professional identities as evidence-based practitioners (Barends \& Briner, 2014; Wright et al., 2016a) and business schools function as identity workspaces for professional education (Petriglieri \& Petriglieri, 2010).

These emerging ideas about the place of EBMgt in the professional education of management students require further research and development. The most pressing need for research lies at the undergraduate end of the novice-expert pathway where the potential to meaningfully teach EBMgt is subject to debate. As Rousseau and McCarthy (2007: 97) ask, 'Can the value of EBMgt techniques be appreciated by individuals with no managerial experience?’ The professional education literature recommends introducing the principles of professional practice, including evidence-based practice, as early as possible so that students become familiar with what they are expected to know and be able to do as a professional (Barends \& Briner, 2014; Scanlon, 2011; Ungaretti, Thompson, Miller, \& Peterson, 2015). In a similar vein, some scholars argue that EBMgt 'should be taught at all levels of management education ... [because] the basic principles can be conveyed to and understood by any management school student' (Briner \& Walshe, 2014: 430, italics in original). Yet little empirical evidence exists to support this argument. Scholars know very little about undergraduate 
students' understanding of EBMgt as they are 'taking the first steps along the path to becoming an expert' (Rousseau, 2006: 265) through professional education in business schools.

\section{Push and Pull Approaches to Teaching EBMgt}

Literature conceptualizing EBMgt as a signature pedagogy for educating business students is supported by other literature that offers guidance on concrete practices for teaching EBMgt. These practices can broadly be distinguished into 'push' and 'pull’ approaches (Kepes et al., 2014; Rynes et al., 2014). Push approaches involve management educators presenting students with the best available evidence on a particular topic. Educators can use course and curricula design to 'push' evidence-based principles derived from research onto students, such as designing leadership courses in MBA programs around the most robust and current research findings on the topic of leadership development (Klimoski \& Amos, 2012). Pushing also occurs through teaching resources and textbooks that report research-based principles on topics such as organizational behaviour and human resources management (Latham, 2009; Pearce, 2013; Pfeffer \& Sutton, 2006). Finally, instructors can push best available research findings on a topic onto students during classroom activities, interactions, and discussions (Charlier, 2014; Erez \& Grant, 2014; Rousseau, 2006).

Pull approaches to teaching EBMgt complement push approaches by helping students attain the metaskills and procedural knowledge for evidence-based practice (Rousseau, 2006). Rather than having evidence 'pushed' on them as declarative knowledge about principles and research findings, students are 'pulled' towards scientific evidence by management educators teaching them the general skills and processes of evidence-based practice that can inform decision making about any topic (Goodman, Shayne, \& Wood, 2014; Rynes et al., 2014). Students engage in evidence-based processes themselves by asking a question, acquiring evidence from research findings and local sources, appraising the credibility and trustworthiness of evidence, applying the principles derived from best available evidence to make a decision, and analysing the results (Kepes et al., 2014).

Pull approaches aim to teach students foundational skills in scientific research evaluation and evidence-based processes including conducting systematic reviews (Briner \& Walshe, 2014; 
Tranfield et al., 2003), performing bibliographic searches (Goodman et al., 2014), evaluating the quality of different sources of evidence (Kepes et al., 2014; Reay et al., 2009), and producing local evidence (Dietz et al., 2014). Pull approaches to EBMgt can also be incorporated into teaching practices already used by management educators. For example, students can be asked to apply evidence-based processes to analyse business case studies (Gamble \& Jelley, 2014; Goodman \& O'Brien, 2012), current events (Wright et al., 2013), decisions made while playing business simulations (Rousseau \& McCarthy, 2007), and problem-based learning (Ungaretti et al., 2015).

Reporting of push and pull approaches in the literature has tended to take an educatorfocused perspective. Scholars make claims that teaching using push and pull approaches can ‘convince students’ about the utility of EBMgt (Erez \& Grant, 2014: 115) and that students 'come away with ... a respect for evidence and an understanding of the basic principle of evidence-based practice’ (Barends \& Briner, 2014: 482). However, these claims are typically based on educators' first-person accounts rather than systematic collection and analysis of student accounts. Data on whether students are convinced by EBMgt, and what their understanding is after being exposed to EBMgt by course instructors, are ‘sparse’ (Dietz et al., 2014: 410). Even though proponents of EBMgt tend to position 'stories as an untrustworthy form of evidence’ (Morrell \& Learmonth, 2015: 530), most reporting of the impacts of push and pull approaches on student learning can be characterized as educator’s personal stories (e.g. Briner \& Walshe, 2014; Charlier, 2014; Dietz et al., 2014; Erez \& Grant, 2014; Rousseau, 2006). Moreover, these educator stories tend to cluster at the MBA and postgraduate levels. While scholars argue that their push and pull approaches for teaching EBMgt have utility for student learning at the undergraduate level (Briner \& Walshe, 2014; Erez \& Grant, 2014; Rousseau, 2006), the literature is relatively silent on undergraduate student perspectives and their experiences of push and pull approaches.

\section{Student Learning and EBMgt}

Together, professional education pedagogy and push-pull approaches offer an invaluable starting point for teaching EBMgt. However, what is missing from the literature is a student point of 
view on EBMgt. Mirroring Morrell and Learmonth’s (2015) criticism of the EBMgt literature for its privileging of the interests of managers, we note that educator's perspectives dominate the literature on teaching and learning about EBMgt. Moreover, just as Reay et al. (2009: 13) called out scholars for overreliance on 'opinion pieces advocating the use of EBMgt', we note a similar weakness in the development of EBMgt pedagogy where little systematic data has been collected and analysed.

Recognising the irony of the dearth of evidence supporting EBMgt teaching practices, some scholars have cautioned that educator claims about impacts on student learning 'should be taken with a grain of salt’ and require more rigorous evaluation (Erez \& Grant, 2014: 117).

We propose that a worthwhile next step in generating research-based knowledge of student learning about EBMgt is to focus empirical investigation on students’ understanding of EBMgt. Student learning in academic disciplines is 'fundamentally about changes in understanding of reality and ... [coming] to understand phenomena in the way that subject experts do’ (Ramsden, 2003: 31). Not surprisingly, then, a common theme in the EBMgt literature is that understanding is a learning goal of highest priority. For example, Graen (2009: 255) argues that management educators have as 'our primary responsibility ... to prepare management students to understand EBMgt well enough to use it'. Other scholars similarly note that educators 'need to help these students understand how to utilize EBMgt within their studies’ (Baack, Miller, Williams, Dierdorff, \& Bielmeier, 2007: 144) and to understand that 'evidence-based practice is a way of looking at the world' (Barends \& Briner, 2014: 481) and 'a way of thinking' (Pfeffer \& Sutton, 2006: 219). Elaborating further on the priority for student understanding of EBMgt, Rousseau and McCarthy (2007: 97) note 'our goals are learner awareness, appreciation, and active use of relevant high-quality evidence’.

To better examine student understanding of EBMgt, we concentrate our attention in this article on undergraduate students. Specifically we ask: How do undergraduate students understand EBMgt? As noted previously, improving EBMgt pedagogy requires deeper insight into how novice undergraduate students understand EBMgt when they are first exposed to evidence-based practice in 
the early stages of professional education in business schools. Our focus on undergraduate student understanding of EBMgt is guided by this definition:

Learning in educational institutions should be about changing the ways in which learners understand, or experience, or conceptualize the world around them. The 'world around them' includes the concepts and methods that are characteristic of the field of learning in which they are studying ... From this point of view, the vital competences in academic disciplines and the application of knowledge consist in understanding. By understanding, I mean the way in which students apprehend and discern phenomena related to the subject (Ramsden, 2003: 6, italics in original).

In the remainder of the article, we explore undergraduate students' understanding of EBMgt through a qualitative inductive study. In doing so, we seek to build on the existing literature concerning professional education pedagogy and push and pull approaches by bringing a student perspective to teaching and learning of EBMgt. This is an important contribution because 'we can only improve the quality of [EBMgt] education if we study its effects on students and look at the experiences through their eyes’ (Ramsden, 2003: 20).

\section{METHOD}

\section{Research Setting and EBMgt Educational Intervention}

The research was conducted in an Introductory Management course at a large university in a major Australian city. The course is mandatory in the AACSB-accredited undergraduate business management and commerce programs and is generally taken by students in the first year of their program of study. Taught over a 13 week semester, the primary course objective is to introduce novice business students to foundational management theories on the planning, organizing, leading and controlling functions of management, and their use in practice. Student enrolments are typically in excess of 1200 students, with students required to attend a two-hour lecture and a one-hour tutorial each week. The course lecturer delivers multiple lectures each week to groups of 400 students and a team of teaching assistants present tutorial classes to groups of 20 students. Of the four authors of this paper, one was the course lecturer, while another worked as a course tutor. The other authors were not involved with the delivery of the course. 
The concept of EBMgt was first introduced in a lecture in the second week of the course. Students then read Rousseau and McCarthy's (2007) article about educating managers from an evidence-based perspective as preparation for small-group discussions in the tutorial. After this initial familiarization with EBMgt, students participated in an online simulation to provide a shared experiential context for subsequent application of EBMgt (Proserpio \& Gioia, 2007). Two criteria guided the choice of simulation. First, students in the course needed to be able to 'demonstrate and practice the relevant competencies’ in the simulation (Salas, Wildman, \& Piccolo, 2009: 565). Simulations without a competitive industry context and which do not require specialized business knowledge are more appropriate for developing the general problem-solving skills of novice business students (Lovelace, Eggers, \& Dyck, 2016; Thompson et al., 1997). Second, because of limited time available in the curriculum, the simulation needed to engage student interest in a single session of play. Research shows simulations that are team-based and have a storyline linked to crisis situations engage students both cognitively and socioemotionally (Doh, 2009; Waller, Lei, \& Pratten, 2014).

The 'Leadership and Team Simulation: Everest V2’ released by Harvard Business Publishing satisfied these criteria. The simulation storyline centres on a virtual commercial expedition to climb Mount Everest, with participants assigned to different roles on five-person teams which hike through five camps to the summit through successive rounds of play. Participants strive to achieve individual and team goals as they make decisions during each round of play and accommodate for asymmetric information and dynamic constraints such as weather, physical health, resources, time and risk of death. Students played the simulation during a single class session in computer laboratories under the supervision of course teaching staff. Students were asked to adopt the persona and goals of their assigned role and to discuss and negotiate decisions within their hiking team, keeping a record of team discussion and the factors influencing decisions in a logbook.

After participating in the simulation, students applied an EBMgt approach to their experience by completing the following tasks. Students reviewed their simulation log book and identified problems which they perceived had the potential to be solved or explained using 
management theory and evidence. Examples of problems included team culture and managing environmental uncertainty in decision making. Students then searched in the scholarly management literature for journal articles containing findings to inform their understanding of their identified problem and to gain insights to resolve it. The task description provided a list of peer reviewed journals to delimit the search boundaries to quality sources of evidence.

Identifying relevant journal articles, students wrote an analysis applying each article’s findings and frameworks to their simulation experience and evaluating if and how their decision making could have been improved by the application of this evidence. Students were also required to read the Rousseau and McCarthy (2007) article in the context of their own attempt at applying an EBMgt approach and to reflect on whether or not they would use EBMgt in their future careers. The design of this reflective task was guided by Trank’s (2014) suggestion that EBMgt educators should pay attention to how students read different interpretations into scholarly journal articles based on personal experience. To encourage students to reflect meaningfully on their experience of EBMgt (Pavlovich, Collins, \& Jones, 2009), students were provided with two guiding questions and asked to write in first person voice (Varner \& Peck, 2003). The guiding questions were 'Based on your experience completing this assignment, what are your thoughts on evidence-based management?' and 'Do you think you will use an Evidence-Based Management approach when you face management-type problems throughout your future career?' The total word length for the written assignment was 2000 words and the assignment weighting represented $25 \%$ of the final course grade. 400 words were allocated to the student's personal reflection on their own experience of applying EBMgt.

\section{Research Instrument and Limitations}

Students’ written reflections on their experience with EBMgt provided a source of empirical material to investigate our research question. These written reflections were an appropriate data source about student understanding of EBMgt for three reasons. First, reflective writing tasks are used by students to express how they make sense of management concepts and practices (Cunliffe, 
2004; Pavlovich et al., 2009) and provide a formalized means for students to offer an 'authentic' account of their experiences to course lecturers (Eriksen, 2012). Because written reflections offer ‘valuable insight into what students are learning’ (Varner \& Peck, 2003: 58), they provide empirical material on the qualitatively different ways that students understand EBMgt, the phenomenon of interest in our study.

Second, prior empirical studies in management education have shown that students' written reflections completed as part of course assessment have 'interpretive validity’ (Maxwell, 1992) as meaningful accounts of student learning, which makes them suitable for use as 'research instruments' for investigating differences in student understanding (Carson \& Fisher, 2006; Dyer \& Hurd, 2016; Lovelace et al., 2016). Prior research also shows that students vary in the depth of reflection, as displayed in writing tasks (Dyer \& Hurd, 2016; Dyment \& O'Connell, 2011). Since our research purpose relies on exploring differences in student understanding of EBMgt, variations in the depth of students’ written reflections are theoretically salient.

Third, in comparison to contemporaneous reflections written at the time of a student's immediate experience with using EBMgt, alternative forms of data collection suffer from retrospective biases that would reduce their reliability. Under the university’s ethics approval processes, student interviews and/or surveys could not be conducted until after all course grades were released, which would produce a two month lag between when students applied EBMgt processes during the assignment and when they would report on their experience in an interview or survey. This time delay between their experience of EBMgt and their reporting of it could generate retrospective biases including inaccurate recall and simple lapses of memory, as well as faulty post hoc attributions and rationalisations in response to grading outcomes (Golden, 1992; Short, Ketchen, Combs, \& Ireland, 2010). Thus, we deemed students’ within-course and pre-grading written reflections to be a more reliable research instrument than the alternative of interviews or surveys conducted after course completion. 
However, a limitation of assessable written reflections as empirical data is the potential for social desirability bias (Varner \& Peck, 2003). Students may present a favourable opinion of EBMgt in their written reflection in anticipation of gaining marker approval and a higher grade. Accordingly, we used three signalling strategies to reduce social desirability bias. First, since choosing to assess reflective writing tasks sends a signal to students about what educators believe is important (Crème, 2005), we encoded signals that honesty and thoughtfulness were required, and would be rewarded, in the grading rubric (Sadler, 2005). Second, the message that students could report disapproval of EBMgt, if this was their personal experience, was communicated in an assignment support lecture presented by the course lecturer and during teaching staff office hours when students came to discuss the assignment. Third, guiding questions in the assignment task description further signalled the lecturer's desire for frank self-assessment and thoughtful reflection of the student's experience of the utility of EBMgt, whether positive or negative (Varner \& Peck, 2003). The candid nature of students' reflective comments suggested these three signalling strategies helped reduce social desirability bias. For example, almost half of the students indicated that EBMgt was not useful or only useful in particular situations. Some students candidly stated they would not 'use their own time to undertake research throughout their studies and career'.

\section{Sampling and Data Collection}

All students enrolled in the course were sent an email one month after the final course grades were released. This email invited students to participate in the study by agreeing to the use of their course assignment - in which students wrote about their understanding of EBMgt immediately after applying evidence-based processes themselves - for research purposes. Consistent with the ethics approval we obtained for the study, students were advised that participation was voluntary and their identity would remain confidential. The data set used for analysis included only those written reflections authored by a student who gave permission for their assignment to be included.

In total, 222 students agreed to participate in the research study, which represents a response rate of over $18 \%$. The participant sample included 74 males and 148 females, which is a slightly 
higher proportion of females than the entire population of students who completed the course. There was no significant difference between the mean mark achieved on the assignment for the participant sample and the mean mark for the course population. The proportions of domestic and international students who participated in the study were also consistent with the course population, which comprises 30\% international students.

\section{Data Analysis}

Our analysis followed well-established procedures for inductively building theory from qualitative data (Corbin \& Strauss, 2008; Denzin \& Lincoln, 2000), along with guidelines for coding and working with student reflection data as suggested by other authors (Dyer \& Hurd, 2016). To improve the trustworthiness and interpretive rigor of the data analysis process (Denzin, 1989), the coding process was led by the first two authors and proceeded in two stages.

In the first stage, we began by reading the entire data-set of reflection texts. One text contained insufficient content to be usable and was removed from the dataset, producing a final dataset for analysis of 221 reflection texts. The first two authors then focused attention on a smaller subset of 50 texts to develop a tentative coding framework. We read each reflection text multiple times and compared within and across these texts looking for similarities and differences in how students described their understanding of EBMgt. This initial coding suggested that student understandings could be broadly distinguished into two groups according to whether EBMgt was comprehended as a way of doing management or a way of being a manager. As we continued our iterative comparisons, we discerned more fine-grained differences among the reflection texts. In particular, we noticed that students expressed qualitatively different understandings of EBMgt as a way of doing or a way of being according to how useful they perceived evidence-based processes to be. We also noticed differences in understandings based upon the stance a student took toward scientific evidence and the focus of their reflection about EBMgt. We tentatively speculated that these three dimensions - utility, stance, focus - could be used as an emergent coding framework to gain deeper insight into the qualitative differences among students in how they understand EBMgt. At this point, the first two authors discussed the emergent coding framework with the other authors. 
This team meeting provided an opportunity to review the data and interrogate and clarify the emergent dimensions of the coding framework.

In the second stage of data analysis, we applied our emergent coding framework to analyse the full dataset of reflection texts. Coding involved grouping together reflection texts that contained claims about EBMgt utility, stance toward scientific evidence, and focus of reflection which were similar to each other and which were qualitatively different to the claims made in the texts that were assigned to other groupings. The first author independently coded one half of the texts, while the second author independently coded the other half. The two authors then switched reflection texts and checked each other's coding, producing a high level of inter-rater agreement of more than 95 per cent (disagreement occurred on the codes assigned to ten reflection texts). Differences were resolved through discussion. Through this coding process, similarities within and differences across the groupings of reflection texts on the three dimensions of utility, stance, and focus clustered around four distinct categories of student understandings of EBMgt. Comparing iteratively within and between the reflection texts and our emergent categories, we challenged each other's perspectives to arrive at the most credible interpretation of our data in response to our research question (Corbin \& Strauss, 2008). Figure 1 illustrates the structure of this coding process as it relates to the emergent dimensions and categories of student understanding of EBMgt.

INSERT FIGURE 1 ABOUT HERE

The first grouping of reflection texts was characterized by an overall understanding of EBMgt as a way of doing management that was unrealistic. Coding indicated low perceived utility, a stance that prioritized intuition over scientific evidence, and personally-focused reflection. We labelled this first form of student understanding EBMgt-as-unrealistic and categorized 27 students into this group. The second grouping of reflection texts was characterized by an overall understanding of EBMgt as a way of doing management that was applicable in particular situations. Coding indicated situational utility, an informative stance toward scientific evidence, and externally- 
focused reflection. We labelled this second form of student understanding EBMgt-as-situational and categorized 75 students into this group. The third grouping of reflection texts was characterized by an overall understanding of management as a way of doing management that was generally useful. Coding indicated general utility, a confirmatory stance toward scientific evidence, and experientiallyfocused reflection. We labelled this third form of student understanding EBMgt-as-useful and categorized 100 students into this group. Finally, the fourth grouping of reflection texts was characterized by an overall understanding of EBMgt as a way of being a manager that was ideal. Coding indicated perceived professional utility, a stance toward scientific evidence as a learning process, and reflection focused on being a member of a profession. We labelled this fourth form of student understanding as EBMgt-as-ideal and categorized 19 students into this group.

A summary of the categories and dimensions of student understanding of EBMgt that emerged from our analysis of the 221 usable reflective texts is presented in Table 1 . The table includes illustrative examples of our data. Each of the categories of student understanding is described in detail in the findings section. The dependability of our coding was increased through the team approach to data analysis, with meetings used to challenge and probe emerging interpretations of our data and display tables assembled to identify and verify patterns in the data (Miles \& Huberman, 1994).

INSERT TABLE 1 ABOUT HERE

\section{FINDINGS}

This section reports the findings of our analysis of our research question of how undergraduate students understand EBMgt. We describe the four understandings of EBMgt as ways of doing and being that emerged from our analysis using the dimensions outlined in Table 1: perceived utility of evidence-based processes, stance toward scientific evidence as a form of knowledge, and the focus of reflection about EBMgt practice. We identify the reflections of individual student participants using alphanumeric codes (e.g. S1, S2) to show that our interpretations 
are grounded in specific empirical material and that parallel meanings emerged from a breadth of data sources (Johnson \& Harris, 2002).

\section{EBMgt is an Unrealistic Way of Doing Management}

The first category of understanding comprised students who comprehended EBMgt as an “unrealistic” (S9) way of doing management. These students perceived EBMgt had little utility for the practice of management inside real organizations. Arguing "it would be difficult to utilise the idea at this point in time” (S20), students supported their judgment of low utility by emphasising the barriers to implementation. Major barriers recognised were the time and cost involved in accessing research evidence and databases: "finding evidence is a tedious ordeal” (S22). Students also emphasised the unreliability of using evidence-based principles derived from past patterns in the dynamic and "unpredictable” environment of modern business (S6) and the absurdity of applying ideas from medicine to "cure organization bodies” (S27). Dismissing evidence-based processes as "impractical” (S9) and "hypothetical” (S8), students perceived low utility for EBMgt in management decision making in organizations because “the costs outweigh the benefits” (S21).

Students who understood EBMgt as unrealistic way of doing management adopted a stance that scientific evidence was inferior to intuition as a form of knowledge. These students refused to attribute legitimacy to evidence published in academic journals "simply because it is science and 'proven'” (S19). Instead, they prioritised personalised forms of knowledge based on human intuition and experience over more abstract scientific evidence. One student, for example, stated, "I’d rather use experience and intuition to make a risk-based assessment, as opposed to evidence” (S5). Another student posited that acquisition of scientific knowledge through evidence-based research “cannot change the way we think and, at the end of the day, we will make our decisions no matter how much research we do” (S17). Privileging of experiential knowledge over scientific knowledge, and of intuitive judgment over EBMgt decision processes, is echoed in this extract from a student reflection:

I believe that this gap between what we should do according to science and what we ultimately [end] up doing is due to basic human nature, meaning that we are prone to following our instinct or our gut feeling. ... I speak from my own experience in saying that statistics, research and 
evidence may have an influence on our decisions, however, humans often choose to do what they ultimately feel is best, regardless of whether it is proven by science. (S16).

Finally, the focus of reflection for students in the EBMgt-as-unrealistic group was personal. That is, when imagining and reflecting on the practice of EBMgt, students focused on the personal and human aspects of doing management work "in my future” (S1). Consistent with their pragmatic approach to EBMgt, students reflected on the circumstances of "real life” (S14) both inside and outside organizations, including anticipated roles beyond the workplace. Students questioned, for example, whether they would have "enough time” (S11, S14) to implement EBMgt given they expected to have "children; husbands; wives; mortgages; sports; hobbies and interests outside of work” (S15). The personally-focused reflection of students who understood EBMgt as an unrealistic way of doing management is illustrated below:

I guess the problem that comes with EBMgt is the ongoing time and effort you have to put into finding appropriate research, reading, understanding and application. If I have a demanding job, family and other commitments, will I make it a priority? If it is not accessible then I most likely will not use EBMgt. (S19)

\section{EBMgt is a Way of Doing Management in Particular Situations}

The second category of understanding of EBMgt identified in our analysis represented those students who understood EBMgt as an appropriate way of doing management in "certain situations" (S58). Whereas students in the EBMgt-as-unrealistic group saw evidence-based processes as lacking practical utility in real organizations, students in this group judged the utility of EBMgt as situationally defined. They perceived that EBMgt was likely to be "beneficial” for decision making and problem solving in some organizational situations and "irrelevant” (S89) in other situations. When justifying why their future usage of EBMgt was expected to be “very situation based” (S56), these students identified situational parameters related to whether the decision was "time sensitive" (S80), the "nature of the problem" (S66), and the level of "experience” (S78) of the decision-maker. EBMgt would be employed, for example, "early in my career” (S87), when "a problem is generic" (S89), and "when there is sufficient time to implement EBM fully" (S88). In contrast, EBMgt was less likely to be employed when problems required evidence that "may not be readily available” (S46), when "fast” (S51) decision responses were required, and when EBMgt was not "the norm" 
(S79) within an organization. Interestingly, some students who understood EBMgt as a situational way of doing management advocated for the necessity of using EBMgt when situations were “ambiguous” (S67), while others distrusted EBMgt when conditions were "uncertain” (S81) or “dynamic” (S86).

Students in the EBMgt-as-situational group took an informative stance toward scientific evidence as a form of knowledge. These students recognised scientific evidence as "information" (S49) that could help managers to "make a better and more informed decision" (S73). Students used the terms "information / evidence" (S79) interchangeably, and tended not to distinguish scientific evidence generated by management research from other sources of local evidence and information such as “statistics and data” (S83), "data collected from the immediate environment” (S88) and "factual knowledge" (S72). Unlike the students in the EBMgt-as-unrealistic group who privileged knowledge developed from experience and intuition, students who understood EBMgt as a situational way of doing management recognised scientific research evidence as a legitimate form of knowledge that supported decision making “in particular scenarios” (S53).

Finally, the focus of reflection for students in the EBMgt-as-situational group was external. When reflecting on their potential future practice, these students focused externally on the organizational and environmental factors that would determine whether or not they adopted evidence-based decision processes. They reflected on, for example, factors in the organizational context that could constrain or enable their ability to implement EBMgt, including "restrictions placed within a workplace” (S55), "the corporate culture of my organization” (S59), and the "beliefs or preferences of [my supervising] manager” (S64). Alongside organizational factors, students reflected on broader environmental factors and "societal expectations" (S77) that could increase dissemination of EBMgt, including how trends in management education determine "whether or not my fellow employees will be well-versed in this practice” (S213). Externally-focused reflection on evidence-based practice supported students’ understandings of EBMgt as a situational way of doing management. 


\section{EBMgt as a Generally Useful Way of Doing Management}

The third category of understanding of EBMgt involved those students who understood EBMgt as a generally useful a way of doing management. In contrast to students in the EBMgt-assituational group who specified situational boundaries around the practice of EBMgt, students in this group perceived EBMgt as having broad utility and practical application to "countless issues” (S121) and "many different problem-solving scenarios" (S97). For these students, EBMgt was a "practical and resourceful technique” (S109) for management decision making that could be applied "to every problem or issue I come across” (S189). Students judged the utility of EBMgt based on expected outcomes of improved management and organizational performance. For example, EBMgt could “allow me to find the best solution in most, if not all, managerial problems” (S105) and, for organizations, will “save time and effort by minimising the use of ineffective approaches” (S108) and "facilitate the development of more effective processes" (S111).

Students who understood EBMgt-as-useful took a confirmatory stance towards scientific evidence. They conceptualized scientific evidence as a form of knowledge that functioned to justify decisions or confirm initial intuitions. Students described how scientific evidence could be collected and evaluated to “prove and check” interpretations (S102), “verify my reasoning” (S134), and “increase certainty and confidence” in decisions (S139). In contrast to the EBM-as-situational group who equated scientific evidence with information, students in the EBMgt-as-useful group differentiated scientific evidence as a special kind of knowledge that arose from "correctly executed, objective scientific testing” (S107) and which was superior to “an intangible response such as emotion” (S120). The following extract highlights the confirmatory stance towards scientific evidence adopted by students who understood EBMgt as a generally useful way of doing management:

I believe this approach would promote confidence in decision-making... Rather than feeling out of control and potentially flustered by a new and unfamiliar set of problems, I can refer to empirical evidence to support and better inform what might otherwise be a trial and error method of problem solving. (S137) 
Finally, the focus of reflection for students in the EBMgt-as-useful group was experiential. When reflecting on their potential future practice with evidence-based processes, students focused on their "involvement in the Everest Simulation" (S96), and "experience in completing the assignment” (S102). Students noted that "when making the decisions for the simulation not much thought went into the who, what, when, where and how" (S127). Yet after applying "research based evidence to [evaluate] my own problems during the Everest Simulation” (S107) and reflecting on their experience with evidence-based processes, students came to understand EBMgt as a "useful decision-making tool” (S112) with the potential to help "bypass ineffective management practices" (S138). Our data suggest that experientially-focused reflection helped these students to make EBMgt meaningful as a generally useful way of doing management. For example, as one student reflected, "the poor problem solving skills relied upon in the simulation [because we did not apply EBMgt before playing] is one of the reasons why I will use an EBMgt approach” (S121). The quote below further illustrates the experientially-focused reflection of students who understood EBMgt as generally useful:

The post-Everest simulation research activity has demonstrated [EBMgt's] ability to become a useful tool for managers...As the simulation demonstrated, without the correct managerial knowledge, the [novice] group made several managerial 'mistakes'. These issues led to inefficiency in reaching team goals, however upon researching evidence-based management articles, it was clear that there were some corrective actions that the group could have taken in the simulation by following what was found in these studies. (S110)

\section{EBMgt as an Ideal Way of Being a Manager}

The final category involved students who understood EBMgt as an ideal way of being a manager. In contrast to the previous three groups of students who understood EBMgt as way of doing, students in the EBMgt-as-ideal group understood EBMgt as a way of being that was linked to their self-identity as a future professional manager. Students in this group perceived the utility of EBMgt was embodied in professional users. These students understood EBMgt as the "ideal” (S39) way of being a manager and believed that developing into an evidence-based practitioner was a "vital component of becoming a successful manager” (S29) and “a professional leader” (S40). 
Students in the EBMgt-as-ideal group took a learning process stance towards scientific evidence as a form of knowledge. Compared to the confirmatory stance of students who understood EBMgt as generally useful, students who understood EBMgt as a way of being apprehended scientific evidence as a "personal knowledge bank” (S40) that was intimately linked to an individual’s “skills and knowledge” (S27). Scientific knowledge was incorporated into the self through activities such as “developing critical thinking ability and decision awareness” (S29) and staying "up to date with current research and findings in the management field” (S30). As a result, students in the EBMgt-as-ideal group understood the evidence-based manager as somebody who integrated scientific evidence into an ongoing process that involved "continued training and understanding of relevant research” (S35) and “reflecting upon this learning” (S42).

Finally, students who understood EBMgt as an ideal way of being a manager engaged in reflection that focused on membership within a profession. Some students in the EBMgt-as-ideal group were enrolled in dual degrees and had already begun developing nascent professional identities in their non-business courses in law (S28), dental science (S31), health science (S34), engineering (S30), and physiotherapy (S33). These students understood evidence-based practice as an "obvious” (S34) and "intelligent way" (S31) of signalling belonging to a profession that was equally relevant to management as it was to traditional professions like "medicine and education" (S28). Students in the EBMgt-as-ideal group who were not training in recognised professions also engaged in reflection focused on membership in a profession. For these students, their reflection focused on their identity as “future managers" and articulated a desire for management to professionalise and not be “excluded from scientific approaches” that would develop professional managers into evidencebased practitioners (S32). Focusing reflection on professional identity and membership of a profession supported students' understanding of EBMgt as an ideal way of being a manager, as illustrated in this quote:

I think that in my future career I will have a strong focus on facing management-type problems with EBMgt ... As a future engineer, it is likely that I will end up in a management-based career. EBMgt is very much in line with the thinking of engineers, where they can use past study and research and apply it in their working life. (S30) 


\section{Summary}

Students' understanding of and reflections about EBMgt vary on the dimensions of perceived utility of EBMgt, stance toward scientific evidence as a form of knowledge, and the focus of reflection. Understanding of EBMgt as an unrealistic way of doing management is characterized by perception that EBMgt is not useful, a stance towards scientific evidence as inferior to intuition, and a personally-focused reflection. Understanding of EBMgt as a way of doing management that is applicable in particular situations is characterized by perceived situational utility of EBMgt, an informative stance towards scientific evidence, and an externally-focused reflection. Understanding of EBMgt as a generally useful way of doing management is characterized by perceived general utility, a confirmatory stance towards scientific evidence, and an experientially-focused reflection. Finally, understanding of EBMgt as an ideal way of being a manager is characterized by perception that EBMgt has utility for professional users, a learning process stance towards scientific evidence, and a reflection that is focused on being a member of a profession.

\section{DISCUSSION}

In this paper, we sought to advance the literature on teaching and learning of EBMgt by investigating: How do undergraduate students understand EBMgt? Our inductive qualitative study of students in a first-year undergraduate introductory management course identified four qualitatively different understandings of EBMgt: 1. EBMgt is an unrealistic way of doing management; 2. EBMgt is a way of doing management in particular situations; 3. EBMgt is a generally useful way of doing management; and 4. EBMgt is an ideal way of being a manager. We find that variations in student understanding are shaped by perceptions of the utility of EBMgt, the stance taken toward scientific evidence, and the focus of reflection about evidence-based practice. By opening up insight into how undergraduate students understand and make sense of EBMgt after being introduced to and applying evidence-based processes early in their program of study, we contribute to the theoretical literature on EBMgt and to the practice of EBMgt teaching and learning, as well as offering new paths for future research. 


\section{Theoretical Contributions}

Our first major theoretical contribution to the literature, in the broadest sense, is to offer a student perspective on EBMgt. Scholars have previously made unsupported claims that push and pull approaches to teaching EBMgt are effective in promoting student learning (Barends \& Briner, 2014; Briner \& Walshe, 2014; Charlier, 2014; Erez \& Grant, 2014; Rousseau, 2006; Rousseau \& McCarthy, 2007). In response, our study subjects the claimed relationship between EBMgt teaching practices and student learning to rigorous empirical examination, and in doing so explores whether it is possible to teach EBMgt meaningfully at the undergraduate level. We focus on student understanding as a fundamental aspect of student learning that is widely recognised in the education literature (Biggs, 1999; Entwhistle \& Tait, 1990; Marton, Hounsell, \& Entwhistle, 1984; Perkins, 1999; Ramsden, 2003; Wright \& Hibbert, 2015). Specifically, we investigate the impact of one form of pull approach - students applying an evidence-based process to examine a problem experienced during a simulation - on student understanding of EBMgt. By extricating how the pull approach creates qualitatively different student understandings of EBMgt as ways of doing and being, our study offers a deeper and more nuanced explanation of the relationship between EBMgt teaching approaches and student learning.

Our findings show that EBMgt teaching does not produce a single consistent understanding of EBMgt across all students. Instead, variations in student understanding arise as each student makes sense of their own individual experiences with applying evidence-based processes. The four variations of student understandings we uncovered broadly confirm first-person accounts and speculations from educators in the literature that some students will resist EBMgt if evidence is not accessible, whereas others are more readily convinced by the value of using scientific evidence to inform management decision making (Briner \& Walshe, 2014; Erez \& Grant, 2014; Rousseau \& McCarthy, 2007). In the breakdown of our data, we found much higher frequencies for the understandings of EBMgt-as-situational (34\%) and EBMgt-as-generally-useful (45\%) compared to the EBMgt-as-unrealistic (12\%) and EBMgt-as-ideal (9\%). While the scale, scope and design of our 
study prevents us attributing causal explanations to these frequency distributions, we offer some tentative speculations about the general patterns as we elaborate our contributions to the literature.

Overall, our findings build on and extend the literature by showing that students create the meaning of EBMgt for themselves through how they apprehend the utility of EBMgt, what stance they take towards scientific evidence, and where they focus their reflection of evidence-based practice. We find, for example, that students who understand EBMgt as situational and general ways of doing management, respectively, adopt stances toward scientific evidence as informative and confirmatory and engage in externally-focused and experientially-focused reflections. We speculate that of the three understandings of EBMgt as a way of doing, EBMgt-as-unrealistic broke out as the smallest category relative to the situational and generally-useful categories because it emerges when students focus their reflection on the personal and human aspects of doing work in their own imagined future career and when they consider scientific evidence as inferior to intuition. Few firstyear students might be expected to have sufficient experience and familiarity with business to imagine the work-life constraints that thwart using evidence-based practice on a day to day basis. At the same time, since novice students at the beginning of a university degree program have made a recent and conscious decision to invest in building their knowledge base about a field of study, they are likely to be relatively open to the value of scientific evidence produced by academic research and may be less confident that their own intuition will lead to superior decision making.

Our findings also show that some students construct an understanding of EBMgt as a way of being rather than as a way of doing. Understanding EBMgt as an ideal way of being a manager broke out as the smallest category in our data set because it requires students to reflect on being a member of a profession and to take a stance towards scientific evidence as a learning process. We speculate that since neither of these actions come easily or naturally to first-year undergraduate students at the beginning of their program of study, only a small proportion of first-year students in our data set had the necessary insight - perhaps developed through their prior educational background, interests and/or life experiences - to engage with EBMgt as a way of being. Nevertheless, these findings 
advance scholarly debates on management's status as a profession (Burke \& Rau, 2010; Graen, 2009; Khurana, 2007; Khurana \& Nohria, 2008; Pfeffer \& Fong, 2002; Trank \& Rynes, 2003) and EBMgt as a signature pedagogy (Schulman, 2005; Trank, 2014) by suggesting that a student’s capacity to understand EBMgt as an ideal way of being a manager depends on the extent to which they apprehend management as a profession. Khurana (2007) argues that producing graduates who view themselves as certified members of the management profession with knowledge and skills of benefit to society, rather than as the self-interested 'hired hands' of shareholders, should be the aim of business schools. Our study connects with Khurana’s (2007) argument by suggesting that EBMgt holds the most promise for professionalizing management when students apprehend it as a way of being.

Our data did not allow us to interrogate the relationships between understanding of EBMgt as a way of being and a student's background, including if they had prior exposure to a profession and/or professionalism (Abbott, 1988; Freidson, 2001). However, our data do support the insight that students in the way-of-being group made connections between what managers know and do epistemologically with what managers are ontologically as professionals. These connections were not apparent in the three groups that understood EBMgt as a way of doing. Since making these connections are core to education in professions (Dall'Alba, 2009), our findings suggest deeper theorization and empirical investigation is needed of the mechanisms underpinning student construction of EBMgt as ways of doing and being.

Our second major theoretical contribution is to advance insight into EBMgt teaching and learning at the undergraduate level. While opportunities for EBMgt teaching in executive, MBA, postgraduate and doctoral programs are increasingly recognised (Charlier et al., 2011; Klimoski \& Amos, 2012), scholars have paid limited attention to exploring the possibilities for teaching evidence-based practice at the undergraduate level. Even less attention has been directed to resolving debates about whether EBMgt can be taught meaningfully to undergraduate students (Rousseau \& McCarthy, 2007). Our findings provide a first step to redressing these limitations in the literature. 
First-year undergraduate students in management degrees are both novice university learners (Ramsden, 2003) and ‘apprentice professionals’ in business management (Trank, 2014: 384). Thus, it is easy to dismiss first-year undergraduate students in business schools as lacking the capacity to comprehend and apply evidence-based practice because of their position at the very start of the novice-to-expert pathway. However, our study suggests that it is short-sighted to delay introducing the basic idea of management as an evidence-based practice until undergraduate students have progressed further along the pathway or to ignore teaching EBMgt until postgraduate levels. While the first-year students who participated in our research did not come to understand or value EBMgt in the same way as academic experts, our findings indicate that all of them were able to develop some minimal level of awareness of the existence of scientific evidence for and about management through a pull approach to teaching.

By drawing attention to student learning of EBMgt at the first-year undergraduate level, our findings extend theoretical arguments that EBMgt has the potential to be a signature pedagogy in the management profession (Schulman, 2005; Trank, 2014). Our data showing the differences in student understanding EBMgt as a 'way of being' compared to a 'way of doing' illuminate how the business school context can function as an identity workspace for professional education (Petriglieri \& Petriglieri, 2010). The ability to ‘try on’ professional identities as evidence-based practitioners (Barends \& Briner, 2014; Wright et al., 2016b) supported students in constructing an understanding of EBMgt through focused reflection as a member of a profession. This insight from our study extends the work of other scholars who find that identity shapes how students engage with research evidence (Caprar, Do, Rynes, \& Bartenuk, 2016; Lund Dean \& Jolly, 2012; Trank, 2014).

At the same time, our findings highlight the potential value of pursuing development of EBMgt as a signature pedagogy in management education that encourages students to continuously, as well as critically (Morrell \& Learmonth, 2015), reflect on the ways of doing and ways of being a member of the profession of management (Khurana, 2007). Our study of first-year students suggests that it is important to start reflective engagement with evidence-based practice early in undergraduate 
programs. Students who do not encounter EBMgt until they are enrolled in MBA programs may be less able to understand evidence-based practice as a way of being a manager because their own identities as practitioners are well established (Hibbert \& Cunliffe, 2015) and they may resist research findings that challenge their self-concept (Caprar et al., 2016).

\section{Practical Implications}

Our study has several practical implications for teaching and learning of EBMgt. Our findings encourage educators to adopt a program-level perspective towards EBMgt as a signature pedagogy in management education. First-level introductory management courses, like the one we studied here, are located at the start of the novice-to-expert pathway and can be used to introduce students to evidence-based practice, producing variations in student understandings of EBMgt as ways of doing and being. Subsequent courses along the pathway to graduation could provide further opportunities to practice evidence-based processes and deepen student's knowledge of EBMgt techniques, encouraging reflection and refinement of student understandings of EBMgt as ways of doing and being.

In reviewing the best suite of courses to implement this signature pedagogy, educators will need to consider how introductory and reinforcing experiences with EBMgt can be timed and paced across a student's learning pathway, while maintaining the current breadth of content that is typical in business and management degrees. One option is to integrate evidence-based practice into the teaching of core courses in management, marketing, information systems, finance and strategic management and in advanced courses within majors. This option mirrors the 'integration strategy' often adopted for teaching ethics in business degrees (Baetz \& Sharp, 2004). A second option is to introduce a small number of stand-alone specialist courses in EBMgt into standard business programs. Specialist courses immerse students in a whole-of-course experience of evidence-based processes and techniques, such as systematic reviews (Briner \& Walshe, 2014; Tranfield et al., 2003). While we adopted the first option in this study, we encourage educators and leaders in 
business schools to experiment with combinations of integration and stand-alone options when designing their undergraduate, postgraduate and MBA programs.

Another practical implication of our study concerns the design of learning activities and assessment. Consistent with principles of constructive alignment in education (Biggs, 1999), our findings provide insight into the types of learning activities and assessment tasks that align with an intended learning outcome of changing student understanding of EBMgt. Instructors can facilitate this learning outcome by (1) designing teaching and learning activities that 'pull' students to access and evaluate scientific evidence in published research articles, and (2) assessing the ways of understanding EBMgt using assignment tasks that require students to write up and reflect on their experience applying evidence-based practice. As we showed in our study, one option for aligning learning activities and assessment is to build them around student experiences participating in business simulations appropriate to the level of the course. Examples of suitable simulations for firstyear general management courses include decision making and leadership simulations with nonbusiness contexts, like the Everest Team simulation used in our study, while simulations with competitive industry contexts may be more suited for advanced courses. Given the huge variety of online business simulations available, we encourage educators to adapt the EBMgt pull approach we designed for the Everest simulation to their preferred simulation. Another option is for students to apply EBMgt processes to analyse a business case study. A good example of a case study that illustrates a manager applying an evidence-based decision process is the Fast Track case study of a hospital emergency department (Wright et al., 2016b), although EBMgt pull approaches can be applied to analyse any business case study (see Gamble \& Jelley, 2014 for more information).

Whichever learning activities and assessment an instructor chooses, we recommend they run whole-class debriefs with students afterwards to bring to the surface the different understandings of EBMgt as ways of doing management (EBMgt-as-unrealistic, EBMgt-as-situational, EBMgt-asgenerally-useful) and a way of being a manager (EBMgt-as-ideal). Instructors could also ask students to compare and contrast two or more of the different understandings of EBMgt during formal in-class 
debates or in a written essay. More reflective learning about EBMgt is likely to occur as students discuss and debate the qualitatively different ways of understanding EBMgt and their different perceptions of EBMgt utility, stance toward scientific evidence, and focus of reflection about evidence-based practice.

\section{Limitations and Future Research}

The characteristics of the context we chose for our empirical investigation impose limitations on the generalizability of our findings. Our data collection was focused on one type of approach for teaching EBMgt (pull approach linked to a simulation), one type of course (generalist course that includes EBMgt component) and one type of student (first-year undergraduate). Future research is therefore needed to explore the extent to which the student understandings we uncovered are generalizable to other pull approaches and to push approaches for teaching EBMgt, to other generalist courses and to specialist EBMgt courses, and to other undergraduate students and to postgraduate and MBA students.

Of particular interest in this future research is exploring the relationships between teaching practices, course factors, student factors, and understanding of EBMgt. From a teaching practice perspective, our findings offer support for the value of pull approaches in changing student understanding of EBMgt through active application. However, future research is needed to examine the comparative conditions under which different types of pull approaches and push approaches influence understanding of EBMgt. From a course perspective, future research should explore similarities and differences in how generalist and specialist courses shape understanding of EBMgt as ways of doing and being. It is possible that the immersion and higher engagement of students in specialist EBMgt courses, which also tend to be taught by academic experts in EBMgt, creates greater clustering of understandings around EBMgt as a way of being a professional manager and a generally useful way of doing management in comparison to our study of a generalist introductory course. 
From the perspective of student-level factors, future research is needed to explore the extent to which the relationships we uncovered between understanding of EBMgt and perception of EBMgt utility, stance toward scientific evidence, and reflection focus are potentially generalizable beyond first-year undergraduate students. Of most value would be research investigating these relationships at further points along the novice-to-expert pathway in the undergraduate program, as well as research of MBA and postgraduate students. Moreover, our data do not allow us to theorize about potential interrelationships between how a student perceives utility of EBMgt, what stance they take towards scientific evidence, and where a student focuses their reflection of evidence-based practice. We encourage investigation of these potential interrelationships as well as other individual-level student factors that the education literature suggests may mediate or moderate student conceptual understanding, such as preferred learning style, student motivation and maturity, and academic ability (Biggs, 1999; Entwhistle \& Tait, 1990; Marton et al., 1984; Ramsden, 2003).

Other limitations of our study relate to the form of data we collected. Our data were reflection texts written by students for course assessment purposes. As outlined in the methods section, this data offered the important advantage of capturing student understanding of EBMgt at the point in time when they actually applied evidence-based practice. We carefully followed recommendations in the literature for reducing the social desirability bias that potentially arises with student data generated for assessment purposes (Varner \& Peck, 2003; Dyer \& Hurd, 2016). Nevertheless, we acknowledge this limitation of student reflective data and invite further research to examine the generalisability of our findings using methods of data collection not linked to course assessment, such as surveys or student focus groups and interviews. We acknowledge a further limitation in that our data were collected at a single point in time. Thus, our findings are limited to student understandings of EBMgt as either a way of doing or a way of being at a particular point in their studies, and do not offer insight into the learning processes by which student understandings of EBMgt emerge and are shaped over time. 
We invite future research to examine the dynamics of the learning processes associated with understandings of EBMgt. Consistent with ideas from experiential learning theory (Kolb \& Kolb, 2005; Kolb, 1984) and theories of reflective practice (Hibbert \& Cunliffe, 2015; Schon, 1983), we speculate that as students progressively accumulate experiences with EBMgt through educator teaching practices in different courses, they learn to be more reflective about evidence-based practice and its utility for management as a profession. It is possible that this process of reflection opens students up to an understanding of EBMgt as a way of being a professional manager. Alternatively, it is also possible that repeated exposure to EBMgt enables students to be more critically reflective (Hibbert, 2013). For example, a student may come to question EBMgt as a way of doing management based on essentially positivist assumptions (Learmonth, 2008; Morrell, 2008; Tourish, 2013) and narrow and select hierarchies of evidence (Kepes et al., 2014; Learmonth, 2006; Reay et al., 2009). They may also challenge EBMgt as a way of being a manager that privileges managerialist interests and disempowers employees (Hornung, 2012; Morrell \& Learmonth, 2015). Thus, we speculate that ways of understanding EBMgt are dynamic rather than static. We encourage future research to explore whether understandings of EBMgt change over time and if so, the dynamics of such changes as (1) student's knowledge of management theory and practice develops through their program of study, and (2) student’s lived experiences with organizations grow via teaching practices such as project-based learning, internships, work experience programs, and graduate trainee positions. 


\section{FIGURE 1: Structure of Data Analysis}

\section{Data}

Claims that EBMgt is not useful or realistic because of practical concerns (e.g. "too difficult and costly" S10, "arduous” S8, "not universally reliable” S4)

Statements that intuition and experience are superior to scientific evidence (e.g. "use intuition, instinct and past knowledge" S153, "results of testing can be fabricated" S5)

Reflection about future use of EBMgt focused on human aspects of doing management work (e.g. "we are only human, and intuition and emotions are powerful factors" S9)

Claims that EBMgt is applicable in particular situations (e.g. "under the appropriate conditions" S84, "effective when it is used in the right context” S81)

Statements indicating that scientific evidence is a type of information (e.g. "evidencebased information” S82, "generate new and current information” S55)

Reflection about future use focused on organizational/environmental factors (eg

"whether my manager would want to implement this practice in his/her workplace”S213) 3)

Claims that EBMgt is a generally useful way of doing management with broad application (e.g. "every problem or issue” S189, “caters for countless issues” S121)

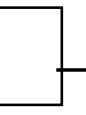

Statements about scientific evidence as able to confirm or verify decisions (e.g. "make my decisions be more persuasive” S119, “support and justify” S127)

\section{$\longrightarrow$ Utility: Situational}

EBMgt (e.g. "during the simulation” S135, "my experience of this assignment” S133)

Claims that EBMgt is an ideal way of being a professional manager (e.g. "become a better manager" S32, “the best leader” S27, "professional leader” S40)

Statements about scientific evidence as an ongoing learning process (e.g. "continual learning” S34, "a skill that is learnt and acquired over time" S36; "adapt” S28)

$\longrightarrow$ Stance: Confirmatory

Reflection about future use of EBMgt focused on being a member of a profession (e.g.

"in my future career as a Dentist” S31, “as a Lean certified Six Sigma Analyst” S29)
Dimensions of Coding

\section{Framework}

\section{Utility: Not useful}

Stance: Inferior to intuition

\section{$\longrightarrow \quad$ Focus: Personal}

Stance: Informative

\section{$\rightarrow \quad$ Focus: External}

\section{$\longrightarrow \quad$ Utility: General}

\section{$\longrightarrow \quad$ Focus: Experiential}

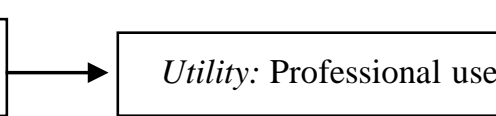

Categories of Student

Understanding

EBMgt-as-

unrealistic

EBMgt-as-

situational

\section{EBMgt-as-}

useful

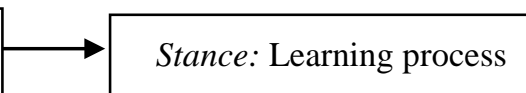

Focus: Member of profession

EBMgt-as-

ideal
How undergraduate students understand

EBMgt 
TABLE 1: Summary of Approaches to EBMgt

\begin{tabular}{|c|c|c|c|c|}
\hline$\overbrace{\text { Dimension }}^{\text {Category }}$ & $\begin{array}{l}\text { EBMgt is an "unrealistic" way of } \\
\text { doing management }\end{array}$ & $\begin{array}{l}\text { EBMgt is a way of doing } \\
\text { management in "particular } \\
\text { situations" }\end{array}$ & $\begin{array}{l}\text { EBMgt is a generally "useful” way } \\
\text { of doing management }\end{array}$ & $\begin{array}{l}\text { EBMgt is the "ideal" way of } \\
\text { being a manager }\end{array}$ \\
\hline $\begin{array}{l}\text { Perceived utility of } \\
\text { EBMgt }\end{array}$ & $\begin{array}{l}\text { Not useful } \\
\text { The vast amount of information } \\
\text { available, and difficulty in obtaining } \\
\text { it, is for me the biggest hurdle. The } \\
\text { search and evaluation of } \\
\text { information is ... frustrating when } \\
\text { relevant information is not readily } \\
\text { available. (S18) }\end{array}$ & $\begin{array}{l}\text { Situationally useful } \\
\text { EBMgt has the potential of being a } \\
\text { useful tool ... for organizations } \\
\text { which are corrupted or achieving } \\
\text { unfavourable results (S66) } \\
\text { When making important decisions } \\
\text { that do not require speed, I would } \\
\text { use EBMgt (S57) }\end{array}$ & $\begin{array}{l}\text { Generally useful } \\
\text { I believe that it is sensible that all } \\
\text { managers use the EBMgt approach to } \\
\text { find solutions to organizational issues. } \\
\text { (S134) } \\
\text { I believe it will assist me in many } \\
\text { different problem-solving scenarios } \\
\text { (S97) }\end{array}$ & $\begin{array}{l}\text { Professional user } \\
\text { EBMgt would be an ideal } \\
\text { management style for me to master } \\
\text { and implement into my daily } \\
\text { practices as a manager. I believe } \\
\text { it will enable me to have a } \\
\text { successful future career (S38) }\end{array}$ \\
\hline $\begin{array}{l}\text { Stance towards } \\
\text { scientific evidence as a } \\
\text { form of knowledge }\end{array}$ & $\begin{array}{l}\text { Inferior to intuition } \\
\text { My evidence will be derived from } \\
\text { first-hand experience and primary } \\
\text { resources as opposed to secondary } \\
\text { sources such as journal articles } \\
\text { (S22) } \\
\text { I would not employ an evidence- } \\
\text { based approach ... I'd rather use } \\
\text { experience and intuition (S5) }\end{array}$ & $\begin{array}{l}\text { Informative } \\
\text { I believe that Evidence-Based } \\
\text { Management is a vital tool in } \\
\text { management, however that in many } \\
\text { cases it would not be applicable. [In } \\
\text { situations when EBMgt is } \\
\text { applicable] it can provide important } \\
\text { outside information that provides } \\
\text { additional information to the } \\
\text { problems (S83). }\end{array}$ & $\begin{array}{l}\text { Confirmatory } \\
\text { I believe the act of justifying each } \\
\text { decision with scientific evidence is a } \\
\text { positive and productive method of } \\
\text { making decisions. (S120) } \\
\text { Managers ... [have] confidence } \\
\text { knowing they have covered all } \\
\text { preliminary research prior to making } \\
\text { the decision; therefore being self- } \\
\text { assured is the right choice” (S112) }\end{array}$ & $\begin{array}{l}\text { Learning process } \\
\text { As soon as I finish my formal } \\
\text { training, to a certain extent, my } \\
\text { continuing education will be at my } \\
\text { discretion. By practicing EBMgt, I } \\
\text { will ensure my ... knowledge and } \\
\text { practice remains relevant. (S31) } \\
\text { [EBMgt gives me] skills to develop } \\
\text { into a better manager as my } \\
\text { career progresses. (S38) }\end{array}$ \\
\hline Focus of reflection & $\begin{array}{l}\text { Personal } \\
\text { I am one of those future business } \\
\text { leaders. I'm taking the kids to pre- } \\
\text { school whilst running out of the } \\
\text { house with a piece of toast out my } \\
\text { mouth, the mail in one hand and } \\
\text { work's briefing notes in the other. I } \\
\text { have so many things going on and I } \\
\text { don't value the importance of } \\
\text { academic journals enough to spend } \\
\text { the time looking at them and then } \\
\text { implementing their suggested } \\
\text { approach (S15) }\end{array}$ & $\begin{array}{l}\text { External } \\
\text { The ethics and cultural environment } \\
\text { of a business will have a significant } \\
\text { impact on the final solution and } \\
\text { can't be compared those of a } \\
\text { different organization. In addition, it } \\
\text { is difficult to apply an EBMgt } \\
\text { approach when a decision is } \\
\text { required within a short period of } \\
\text { time. Due to this, I do think that I } \\
\text { will use an EBMgt approach to } \\
\text { management, however it is not } \\
\text { practical in all situations and in } \\
\text { those cases, a different style will be } \\
\text { used. (S65) }\end{array}$ & $\begin{array}{l}\text { Experiential } \\
\text { Through applying EBMgt to the } \\
\text { Everest simulation I was able to } \\
\text { consider useful strategies we could } \\
\text { have used to enhance our } \\
\text { performance. Therefore, if our group } \\
\text { was to complete the simulation again, } \\
\text { we would certainly benefit from } \\
\text { utilising EBMgt and have a clearer } \\
\text { focus on shared strategies and goals } \\
\text { (S180) }\end{array}$ & $\begin{array}{l}\text { Being a member of a profession } \\
\text { My future plan is to be admitted as } \\
\text { a solicitor, and to eventually } \\
\text { become a partner of a law firm. In } \\
\text { such a position, evidence-based } \\
\text { management would be very } \\
\text { valuable (S162) } \\
\text { As the president of a student run } \\
\text { organisation ... now that EBM has } \\
\text { had an impact on me as a concept, } \\
\text { I believe I will be more likely to } \\
\text { actively search out solutions } \\
\text { available to the problems that I } \\
\text { face as a president (S32) }\end{array}$ \\
\hline $\begin{array}{l}\text { Number of participant } \\
\text { reflections }\end{array}$ & 27 & 75 & 100 & 19 \\
\hline
\end{tabular}




\section{References}

Abbott, A. 1988. The System of Professions: An Essay on the Division of Expert Labor. Chicago, IL: University of Chicago Press.

Baack, S., Miller, S., Williams, J., Dierdorff, E. C., \& Bielmeier, P. 2007. Book review: Hard facts, dangerous half-truths and total nonsense. Academy of Management Learning and Education, 6(1): 139-148.

Baba, V. V., \& HakemZadeh, F. 2012. Toward a theory of evidence-based decision making. Management Decision, 50(5): 832-867.

Baetz, M. C., \& Sharp, D. J. 2004. Integrating ethics content into the core business curriculum: Do core teaching materials do the job? Journal of Business Ethics, 51: 53-62.

Barends, E., \& Briner, R. B. 2014. Teaching evidence-based practice: Lessons from the pioneers. An interview with Amanda Burls and Gordon Guyatt. Academy of Management Learning and Education, 13(3): 476-483.

Bartenuk, J. 2014. Introduction: Bringing life to a correlation of 0.14: Teaching EBM engagingly and convincingly. Academy of Management Learning and Education, 13(1): 102-103.

Benner, P. 1982. From novice to expert. American Journal of Nursing, 82: 402-407.

Biggs, J. B. 1999. Teaching for Quality Learning at University. Buckingham: SRHE and Open University Press.

Briner, R. B., Denyer, D., \& Rousseau, D. M. 2009. Evidence-based management: Concept cleanup time. Academy of Management Perspectives, 23(4): 19-32.

Briner, R. B., \& Walshe, N. D. 2014. From passively received wisdom to actively constructed knowledge: Teaching systematic review skills as a foundation of evidence-based management. Academy of Management Learning and Education, 13(3): 415-432.

Burke, L. A., \& Rau, B. 2010. The research-teaching gap in management. Academy of Management Learning and Education, 9: 132-143.

Caprar, D. V., Do, B., Rynes, S. L., \& Bartenuk, J. M. 2016. It's personal: An exploration of students' (non)acceptance of management research. Academy of Management Learning and Education, 15(2): 207-231.

Carson, L., \& Fisher, K. 2006. Raising the bar on criticality: Students' critical reflection in an internship program. Journal of Managment Education, 30(5): 700-723.

Charlier, S. D. 2014. Incorporating evidence-based management into management curricula: A conversation with Gary Latham. Academy of Management Learning and Education, 13(3): 467-475.

Charlier, S. D., Brown, K. G., \& Rynes, S. L. 2011. Teaching evidence-based management in MBA programs: What evidence is there? Academy of Management Learning \& Education, 10(2): 222-236.

Corbin, J., \& Strauss, A. 2008. Basics of Qualitative Research (Third ed.). Thousand Oaks, CA: Sage.

Crème, P. 2005. Should student learning journals be assessed? Assessment \& Evaluation in Higher Education, 30(3): 287-296.

Cunliffe, A. L. 2004. On becoming a critically reflexive practitioner. Journal of Management Education, 28(4): 407-426.

Dall'Alba, G. 2009. Learning to be Professionals. Netherlands: Springer.

Denzin, N. K. 1989. The Research Act: Theoretical Introduction to Sociological Methods. Englewood Cliffs, NJ: Prentice Hall.

Denzin, N. K., \& Lincoln, Y. S. 2000. Handbook of Qualitative Research (2nd ed.). Thousand Oaks, CA: Sage.

Dietz, J., Antonakis, J., Hoffrage, U., Krings, F., Marewski, J., \& Zender, C. 2014. Teaching evidencebased management with a focus on producing local evidence. Academy of Management Learning and Education, 13(3): 397-414. 
Doh, J. P. 2009. Introduction: The real world via simulation. Academy of Management Learning and Education, 8(4): 558.

Dyer, S. L., \& Hurd, F. 2016. "What's going on?" Developing reflexivity in the management classroom: Fron surface to deep learning and everything in between. Academy of Management Learning \& Education, 15(2): 287-303.

Dyment, J. E., \& O'Connell, T. S. 2011. Assessing the quality of reflection in student journals: A review of the research. Teaching in Higher Education, 16(1): 81-97.

Entwhistle, N. J., \& Tait, H. 1990. Approaches to learning, evaluations of teaching, and preferences for contrasting academic environments. Higher Education, 19: 164-194.

Erez, A., \& Grant, A. 2014. Separating data from intuition: Bringing evidence into the management classroom. Academy of Management Learning and Education, 13(1): 104-119.

Eriksen, M. 2012. Facilitating authentic becoming. Journal of Management Education, 36(5): 698736.

Freidson, E. 2001. Professionalism: The Third Logic. Chicago, IL: University of Chicago Press.

Gamble, E., \& Jelley, B. 2014. The case for competition: Learning about evidence-based management through case competition. Academy of Management Learning and Education, 13(3): 433445.

Glaub, M. E., Frese, M., Fischer, S., \& Hoppe, M. 2015. Increasing personal initiative in small business managers or owners leads to entrepreneurial success: A theory-based controlled randomized field intervention for evidence-based management. Academy of Management Learning and Education, 15(1): 21-46.

Golden, B. R. 1992. The past is the past - Or is it? The use of restrospective accounts as indicators of past strategy. Academy of Management Journal, 35: 848-860.

Goodman, J. S., \& O'Brien, J. 2012. Teaching and learning using evidence-based principles. In D. M. Rousseau (Ed.), The Oxford Handbook of Evidence-based Management 309-336. New York: Oxford University Press.

Goodman, J. S., Shayne, G. M., \& Wood, R. E. 2014. Bibliographic search training for evidence-based management education: A review of relevant literatures. Academy of Management Learning and Education, 13(3): 322-353.

Graen, G. B. 2009. Educating new management specialists from an evidence-based perspective: A proposal. Academy of Management Learning and Education, 8(2): 255-258.

Hibbert, P. 2013. Approaching reflexivity through critical reflection: issues for critical management education. Journal of Management Education, 37(6): 803-827.

Hibbert, P., \& Cunliffe, A. L. 2015. Responsible management: Engaging moral reflexive practice through threshold concepts. Journal of Business Ethics, 127(1): 177-188.

Hornung, S. 2012. Beyond 'new scientific management': Critical reflections on the epistemology of evidence-based management. In D. M. Rousseau (Ed.), The Oxford Handbook of Evidencebased Management: 389-403. Oxford: Oxford University Press.

Johnson, P., \& Harris, D. 2002. Qualitative and quantitative issues in research design. In D. Partington (Ed.), Essential Skills for Management Research: 99-116. Thousand Oaks, CA: Sage.

Kachra, A., \& Schneitz, K. 2008. The capstone strategy course: What might real integration look like. Journal of Management Education, 32(4): 476-508.

Kepes, S., Bennett, A. A., \& McDaniel, M. A. 2014. Evidence-based management and the trustworthiness of our cumulative scientific knowledge: Implications for teaching, research, and practice. Academy of Management Learning and Education, 13(3): 446-466.

Khurana, R. 2007. From Higher Aims to Hired Hands: The Social Transformation of American Business Schools and the Unfulfilled Promise of Management as a Profession. Princeton: Princeton University Press.

Khurana, R., \& Nohria, N. 2008. It's time to make management a true profession. Harvard Business Review, 10. 
Klimoski, R., \& Amos, B. 2012. Practicing evidence-based education in leadership development. Academy of Management Learning and Education, 11(4): 685-702.

Kolb, A. Y., \& Kolb, D. A. 2005. Learning styles and learnign spaces: Enhancing experiential learning in higher education. Academy of Management Learning and Education, 4(2): 193-212.

Kolb, D. A. 1984. Experiential Learning Theory: Experience as the Source of Learning and Development. Englewood Cliffs, NJ: Prentice Hall.

Kovner, A. R., Elton, J. J., \& Billings, J. 2000. Evidence-based management. Frontiers of Health Services Management, 16(4): 3-22.

Latham, G. P. 2009. Becoming the evidence-based manager: Making the science of management work for you. Boston, MA: Davies-Black.

Learmonth, M. 2006. Dialogue: "Is there such a thing as evidence-based management?": A commentary on Rousseau's 2005 presidential address. Academy of Management Review, 31: 1089-1093.

Learmonth, M. 2008. Evidence-based management: A backlash against pluralism in organizational studies. Organization, 15: 283-291.

Lovelace, K. J., Eggers, F., \& Dyck, L. R. 2016. I do and I understand: Assessing the utility of webbased management simulations to develop critical thinking skills Academy of Management Learning and Education, 15(1).

Lund Dean, K., \& Jolly, J. P. 2012. Student identity, disengagement and learning. Academy of Management Learning and Education, 11(2): 228-243.

Marton, F., Hounsell, D. J., \& Entwhistle, N. J. (Eds.). 1984. The Experience of Learning. Edinburgh: Scottish Academic Press.

Maxwell, J. A. 1992. Understanding and validity in qualitative research. Harvard Educational Review, 62(3): 279-300.

Miles, M. B., \& Huberman, A. M. 1994. Qualitative Data Analysis: An Expanded Sourcebook. London: Sage.

Morrell, K. 2008. The narrative of 'evidence-based management: A polemic. Journal of Management Studies, 45(3): 613-635.

Morrell, K., \& Learmonth, M. 2015. Against evidence-based management, for management learning. Academy of Management Learning and Education, 14(4): 520-533.

Pavlovich, K., Collins, E., \& Jones, G. 2009. Developing students' skills in reflective practice. Journal of Management Education, 33(1): 37-58.

Pearce, J. 2013. Organizational Behavior: Real Research for Real Managers. Irvine, CA: Melvin \& Leigh Publishers.

Perkins, D. 1999. The many faces of constructivism. Educational Leadership, 57(3): 6-11.

Petriglieri, G., \& Petriglieri, J. L. 2010. Identity workspaces: The case of business schools. Academy of Management Learning and Education, 9: 44-60.

Pfeffer, J., \& Fong, C. 2002. The end of business schools? Less success than meets the eye. Academy of Management Learning and Education, 1(1): 78-95.

Pfeffer, J., \& Sutton, R. I. 2006. Hard Facts, Dangerous Half-Truths, and Total Nonsense: Profiting from Evidence-based Management. Boston: Harvard Business Review.

Pfeffer, J., \& Sutton, R. I. 2007. Suppose we took evidence-based management seriously: Implications for reading and writing management. Academy of Management Learning and Education, 6: 153-155.

Proserpio, L., \& Gioia, D. A. 2007. Teaching the virtual generation. Academy of Management Learning and Education, 6(1): 69-80.

Ramsden, P. 2003. Learning to Teach in Higher Education. London: Routledge Falmer.

Reay, T., Berta, W., \& Kohn, M. K. 2009. What's the evidence on evidence-based management? Academy of Management Perspectives, 23(4): 5-18.

Rousseau, D. M. 2006. Is there such a thing as 'evidence-based management'? Academy of Management Review, 31(2): 256-269. 
Rousseau, D. M. (Ed.). 2012. The Oxford Handbook of Evidence-Based Management. New York: Oxford University Press.

Rousseau, D. M., \& McCarthy, S. 2007. Educating managers from an evidence-based perspective. Academy of Management Learning and Education, 6(1): 84-101.

Rubin, R. S., \& Dierdorff, E. C. 2009. How relevant is the MBA? Assessing the alignment of required curricula and required management competencies. Academy of Management Learning and Education, 8: 208-224.

Rynes, S. L., Rousseau, D. M., \& Barends, E. 2014. Change the world: Teach evidence-based practice! Academy of Management Learning and Education, 13(3): 305-321.

Sadler, D. R. 2005. Interpretations of criteria-based assessment and grading in higher education. Assessment and Evaluation in Higher Education, 30(2): 175-194.

Salas, E., Wildman, J. L., \& Piccolo, R. F. 2009. Using simulation-based training to enhance management education. Academy of Management Learning and Education, 8: 559-573.

Scanlon, L. (Ed.). 2011. "Becoming" a professional: An interdisciplinary analysis of professional learning. Dordrecht, Netherlands: Springer.

Schon, D. A. 1983. The Reflective Practitioner: How Professionals Think in Action. New York: Basic Books.

Schulman, L. S. 2005. Signature pedagogies in professions. Daedalus, 134(3): 52-59.

Short, J. C., Ketchen, D. J., Combs, J. G., \& Ireland, R. D. 2010. Research methods in entrepreneurship: Opportunities and challenges. Organizational Research Methods, 13(1): 6-15.

Thompson, T. A., Purdy, J. M., \& Fandt, P. M. 1997. Building a strong foundation: Using a computer simulation in an Introductory Management Course. Journal of Management Education, 21(3): 418-434.

Tourish, D. 2013. "Evidence-based management" or "evidence-oriented organizing"? A critical realist perspective. Organization, 20(2): 173-192.

Tranfield, D., Denyer, D., \& Smart, P. 2003. Towards a methodology for developing evidenceinformed management knowledge by means of systematic review. British Journal of Management, 14: 207-222.

Trank, C. Q. 2014. "Reading" evidence-based management: The possibilities of interpretation. Academy of Management Learning and Education, 13(3): 381-395.

Trank, C. Q., \& Rynes, S. L. 2003. Who moved our cheese? Reclaiming professionalism in business education. Academy of Management Learning and Education, 2(189-205).

Ungaretti, T., Thompson, K. R., Miller, A., \& Peterson, T. O. 2015. Problem-based learning from medical education and challenges for management education. Academy of Management Learning and Education, 14(2): 173-186.

Varner, D., \& Peck, S. R. 2003. Learning from learning journals: The benefits and challenges of using learning journal assignments. Journal of Management Education, 27(1): 52-77.

Waller, M. J., Lei, Z., \& Pratten, R. 2014. Focusing on teams in crisis management education: An integration and simulation-based approach. Academy of Management Learning and Education, 13(2): 208-221.

Wright, A. L., \& Gilmore, A. 2012. Threshold concepts and conceptions: Student learning in introductory management courses. Journal of Management Education, 36(5): 614-635.

Wright, A. L., \& Hibbert, P. 2015. Threshold concepts in theory and practice. , 39(4): 443-451. Journal of Management Education, 39(4): 443-451.

Wright, A. L., Middleton, S., Greenfield, G., Williams, J., \& Brazil, V. 2016a. Strategies for teaching evidence-based management: What management educators can learn from medicine. Journal of Management Education, 40(2): 194-219.

Wright, A. L., Nichols, E., McKechnie, M., \& McCarthy, S. 2013. Combining crisis management and evdience-based management: The Queensland floods as a teachable moment. Journal of Management Education, 37(135-160). 
Wright, A. L., Zammuto, R. F., Liesch, P. W., Middleton, S., Hibbert, P., Burke, J., \& Brazil, V. 2016b. Evidence-based management in practice: Opening up the decision process, decision-maker and context. . British Journal of Management, 26(1): 161-178. 